Article

\title{
Parabiosis Incompletely Reverses Aging-Induced Metabolic Changes and Oxidant Stress in Mouse Red Blood Cells
}

\author{
Evan J. Morrison ${ }^{1}$, Devin P. Champagne ${ }^{1}{ }^{\circledR}$, Monika Dzieciatkowska ${ }^{1}$, Travis Nemkov ${ }^{1}$, \\ James C. Zimring ${ }^{2}$, Kirk C. Hansen ${ }^{1}$, Fangxia Guan ${ }^{3,4}$, Derek M. Huffman ${ }^{3,4,5}$, \\ Laura Santambrogio ${ }^{6}$ and Angelo D'Alessandro 1,7,*(i) \\ 1 Department of Biochemistry and Molecular Genetics, University of Colorado Denver - Anschutz Medical \\ Campus, 12801 East 17th Ave RC1 South, Aurora, CO 80045, USA; evan.morrison@ucdenver.edu (E.J.M.); \\ devin.champagne@ucdenver.edu (D.P.C.); monika.dzieciatkowska@ucdenver.edu (M.D.); \\ travis.nemkov@ucdenver.edu (T.N.); kirk.hansen@ucdenver.edu (K.C.H.) \\ 2 BloodWorks Northwest, Seattle, WA 98104, USA; JZimring@BloodWorksNW.org \\ 3 Departments of Medicine, Albert Einstein College of Medicine, 1300 Morris Park Avenue, New York, \\ NY 10461, USA; fangxia.guan@einstein.yu.edu (F.G.); derek.huffman@einstein.yu.edu (D.M.H.) \\ 4 Institute for Aging Research, Albert Einstein College of Medicine, 1300 Morris Park Avenue, New York, \\ NY 10461, USA \\ 5 Department of Molecular Pharmacology, Albert Einstein College of Medicine, 1300 Morris Park Avenue, \\ New York, NY 10461, USA \\ 6 Department of Pathology, Microbiology \& Immunology, Albert Einstein College of Medicine, 1300 Morris \\ Park Avenue, New York, NY 10461, USA; laura.santambrogio@einstein.yu.edu \\ 7 Department of Medicine-Division of Hematology, University of Colorado Denver-Anschutz Medical \\ Campus, 12469 East 17th Ave RC2, Aurora, CO 80045, USA \\ * Correspondence: angelo.dalessandro@ucdenver.edu; Tel.: +1-303-724-0096
}

Received: 16 April 2019; Accepted: 12 June 2019; Published: 14 June 2019

\begin{abstract}
Mature red blood cells (RBCs) not only account for $\sim 83 \%$ of the total host cells in the human body, but they are also exposed to all body tissues during their circulation in the bloodstream. In addition, RBCs are devoid of de novo protein synthesis capacity and, as such, they represent a perfect model to investigate system-wide alterations of cellular metabolism in the context of aging and age-related oxidant stress without the confounding factor of gene expression. In the present study, we employed ultra-high-pressure liquid chromatography coupled with mass spectrometry (UHPLC-MS)-based metabolomics and proteomics to investigate RBC metabolism across age in male mice $(6,15$, and 25 months old). We report that RBCs from aging mice face a progressive decline in the capacity to cope with oxidant stress through the glutathione/NADPH-dependent antioxidant systems. Oxidant stress to tryptophan and purines was accompanied by declines in late glycolysis and methyl-group donors, a potential compensatory mechanism to repair oxidatively damaged proteins. Moreover, heterochronic parabiosis experiments demonstrated that the young environment only partially rescued the alterations in one-carbon metabolism in old mice, although it had minimal to no impact on glutathione homeostasis, the pentose phosphate pathway, and oxidation of purines and tryptophan, which were instead aggravated in old heterochronic parabionts.
\end{abstract}

Keywords: erythrocyte; metabolism; mass spectrometry; blood; metabolomics

\section{Introduction}

Over the last 160 years, the average life expectancy rose from 45 to $~ 85$ in most industrialized countries [1]. With an increase in longevity worldwide, age-associated non-communicable diseases 
emerged as a substantial burden in disease incidence and healthcare costs [2]. The list of diseases for which age is an independent risk factor includes current leading causes of mortality in the adult population, such as cancer, diabetes, cardiovascular disease, and neurodegenerative diseases [3]. Despite decades of studies on the topic, the identification of strategies to slow the aging process is frustrated by the complex and stochastic nature of progressive biological decay. Indeed, aging is a complex phenomenon, one that is impacted by several factors such as genetics and environment, and their interplay [4]. Variation in lifespan among species or individuals is indeed dictated in part by genetics [5], although environmental factors such as diet [6], exercise [7], or other lifestyle habits (e.g., smoking [8]) are increasingly appreciated as key contributors to aging. All these factors were shown to contribute to mitochondrial dysfunction and systemic oxidant stress $[9,10]$, etiological contributors to many of the cardiovascular, neurocognitive, and inflammatory complications associated with aging. Meanwhile, interventions that succeeded in slowing features of aging, such as dietary restriction (DR) or rapamycin, are able to potently modulate key metabolic pathways, including insulin/Insulin-like growth factor 1 (IGF-1) signaling, AMP-activated protein kinase (AMPK)/mechanistic target of rapamycin (mTOR), and inflammation [3]. Indeed, several recent studies-from animal models to clinical trials [11]—showed that dietary interventions aimed at reprogramming system metabolism could represent a viable strategy to extend the lifespan, or at least to extend the population health span.

Owing to their capillary distribution, red blood cells (RBCs) - the most abundant human cell in our body ( $\sim 83 \%$ of total human cells excluding bacteria [12])—represent a perfect model to investigate system metabolism. While originally considered simple bags of hemoglobin, RBCs are increasingly being appreciated owing to their complex capacity to buffer system metabolism, as a result of their $\sim 3000$ proteins and $\sim 100$ molecular membrane transporters [13]. During their 120-day lifespan in the bloodstream, at full oxygen saturation of the 250-270 million copies of hemoglobin/cell [14], RBCs could transport over one billion/molecules of oxygen per cell-numbers that make it easy to appreciate the likelihood of radical-generating reactions in a cell that is also loaded with $>60 \%$ of bodily iron [15]. In addition, owing to the lack of nuclei and organelles, mature RBCs cannot synthesize new proteins to face sudden or progressive increases in the oxidant stress challenge. As such, RBCs are a perfect model to investigate system metabolism in the context of cellular oxidant stress without the confounding contribution of de novo synthesis of gene products. Interestingly, the very process of increased inflammation and oxidant stress in aged individuals (also referred to as "inflammaging" [16]) is associated with a stressed erythropoiesis phenotype, one that ultimately results in a skewed hematopoietic maturation toward myeloid progenitors [17]—a potential etiological contributor to the so-called "anemia in the elderly" [18].

RBCs are well equipped with antioxidant systems, especially those depending on glutathione. However, studies from the late 1970s identified a progressive decline in the glutathione-dependent RBC antioxidant capacity as a function of organism and RBC age in mice [19]. This decline is in part explained by the progressive deregulation of the pentose phosphate pathway (PPP) in the aging RBCs of the aging organism (mouse or human [20-22]). Indeed, the PPP generates the reducing co-factor Nicotinamide adenine dinucleotide phosphate (NADPH), which is critical for fueling the recycling of several antioxidant systems in RBCs such as glutathione peroxidase, catalase, peroxiredoxins [23], glutaredoxins, thioredoxin reductase system, biliverdin reductase B [24], and the ascorbate-tocopherol axis [25]. Glucose 6-phosphate dehydrogenase (G6PD) is the rate-limiting enzyme of the PPP and, thus, a critical enzyme in NADPH homeostasis in RBCs and other tissues [26]. Nonetheless, $\sim 400$ million people suffer from mutations in G6PD that impact its activity to a variable extent, a condition referred to as G6PD deficiency - the most common enzymopathy in humans [27]. Of note, G6PD activity was suggested to decline with age [20-22], while transgenic mice overexpressing G6PD have improved health spans [28]. However, despite these classic studies, no recent reports addressed this aspect of RBC biology in the context of aging with state-of-the-art omics approaches.

In the last few years, the advent of omics technologies revived interest around blood metabolism as a critical source of information to investigate derangements in system metabolism as a function 
of aging [29]. Recently, we reported the impact of aging on RBC metabolism in a cohort of 97 subjects, including individuals with Down syndrome, the most common human condition due to aneuploidy in the human population (one in $~ 700$ live births in the United States) [30]. Of note, individuals with Down syndrome are more susceptible to several of the comorbidities associated with aging, including neurocognitive diseases (e.g., Alzheimer's disease), several autoimmune and hematological cancers, pulmonary hypertension, and hearing and vision problems [31,32]. Interestingly, RBC lifespan is shortened in individuals with Down syndrome, a phenomenon that is accompanied by metabolic alterations in one-carbon metabolism (and associated damage-repair mechanisms [33]), and glutathione and purine oxidation, as well as tryptophan metabolism [30]-a pathway critical to immunoregulation [34]. Recently, tryptophan catabolites via inflammatory (interferon signaling) and oxidative metabolism were associated with neurocognitive impairment in Down syndrome [35].

Parabiosis, which is a surgical approach for joining the circulatory systems between young-young and old-old (isochronic) or young-old (heterochronic) animals, re-emerged over the past decade in aging research. Studies based on this approach demonstrated that aging occurs as a complex interaction of cell autonomous and cell non-autonomous mechanisms. Using heterochronic parabiosis, cell non-autonomous effects were demonstrated by transposition of aging phenotypes (i.e., old to young, young to old) in several organs and cells, and implicated specific gerontic factors, including beta-2 microglobulin (B2M), C-C Motif Chemokine Ligand 11 (CCL11), and transforming growth factor beta (TGF $\beta$ ), in mediating these effects. Of note, some of the molecular and behavioral signatures associated with neurocognitive decline in aging were restored in old mice exposed to young blood via heterochronic parabiosis [36]. Recent work showed that the young environment ameliorates neurocognitive defects in aging mice, through mechanisms at least in part involving Tet2 and DNA methylation status in the aged hippocampus [37]. Therefore, in the present study, we employed state-of-the-art metabolomics and proteomics technologies to investigate RBC metabolism in mice of six, 15 , and 25 months of age, and to further determine the extent, if any, to which shifts in the metabolome or proteome of the cells are modulated by the systemic environment through heterochronic parabiosis.

\section{Materials and Methods}

\subsection{Aging and Parabiotic Mice}

Parabiosis surgery was carried out by the Einstein Chronobiosis and Energetics/Metabolism of Aging Core in young and old male C57BL/6 mice obtained from the National Institute of Aging aged rodent colony at four or 18 months of age, respectively, as described previously [38,39]. Surgical unions were performed between young (four months old) animals (isochronic; young $(\mathrm{Y})-\mathrm{Y} ; n=4)$, old (18 months old) animals (isochronic old $(\mathrm{O})-\mathrm{O} ; n=5)$, and young and old mice (heterochronic $\mathrm{Y}-\mathrm{O} ; n=5$ ). Following surgery, animals were kept on a partial heating pad overnight. Pairs were then intensively monitored and received subcutaneous (SQ) injections of Banamine $(2 \mathrm{mg} / \mathrm{kg}$ each) immediately post-op and bis in die (b.i.d.) for three days and then once daily for four days. Animals also received $1 \mathrm{~mL}$ of ringer's lactate SQ immediately after, daily for three days post-op to prevent dehydration. Animals remained joined for $\sim 8$ weeks prior to sacrifice. All experimental procedures were approved by the Institutional Animal Care and Use Committee (IACUC) at the Albert Einstein College of Medicine.

\subsection{Metabolomics}

\subsubsection{Sample Extraction}

Metabolomics analyses were performed on $20 \mu \mathrm{L}$ of packed RBCs at 1:25 dilution in separate extractions of with either methanol:acetonitrile:water (5:3:2 v/v) or pure methanol (Optima, Thermo Fisher) prior to vortexing for $30 \mathrm{~min}$ at $4{ }^{\circ} \mathrm{C}$ and centrifugation at $18,000 \times \mathrm{g}$ for $10 \mathrm{~min}$ at $4{ }^{\circ} \mathrm{C}$, as described 
previously $[40,41]$. Extracts were analyzed via ultra-high-pressure liquid chromatography coupled with mass spectrometry (UHPLC-MS).

\subsubsection{UHPLC-MS Analysis}

The analytical platform employs a Vanquish UHPLC system (Thermo Fisher Scientific, San Jose, CA, USA) coupled online to a Q Exactive mass spectrometer (Thermo Fisher Scientific, San Jose, CA, USA), as extensively described in prior work [40,42-44]. Metabolites were separated with a combination of isochratic and gradient-based methods as per protocols extensively detailed in recent methods papers $[45,46]$. Briefly, the analytical platform employs a Vanquish UHPLC system coupled online to a Q Exactive mass spectrometer (Thermo Fisher Scientific, San Jose, CA, USA). Samples were resolved over a Kinetex C18 column, $2.1 \times 150 \mathrm{~mm}, 1.7 \mu \mathrm{m}$ particle size (Phenomenex, Torrance, CA, USA) equipped with a guard column (SecurityGuard ${ }^{\mathrm{TM}}$ Ultracartridge UHPLC C18 for $2.1 \mathrm{~mm}$ inner diameter (ID) Columns; AJO-8782; Phenomenex, Torrance, CA, USA) using an aqueous phase (A) of water and $0.1 \%$ formic acid and a mobile phase (B) of acetonitrile and $0.1 \%$ formic acid for positive ion mode runs, while, for negative ion mode runs, $2 \mathrm{mM}$ ammonium acetate was used to replace formic acid. Samples were eluted from the column using either an isocratic elution of $5 \% \mathrm{~B}$ flowed at $250 \mu \mathrm{L} / \mathrm{min}$ and $25{ }^{\circ} \mathrm{C}$ or a gradient from $0-5 \%$ B over $0.5 \mathrm{~min}, 5-95 \%$ B over $0.6 \mathrm{~min}$, held at $95 \%$ B for $1.65 \mathrm{~min}, 95-5 \%$ B over $0.25 \mathrm{~min}$, and held at $5 \%$ B for $2 \mathrm{~min}$, flowed at $450 \mu \mathrm{L} / \mathrm{min}$ and $35^{\circ} \mathrm{C}$. The Q Exactive mass spectrometer (Thermo Fisher Scientific, San Jose, CA, USA) was operated independently in positive or negative ion mode, scanning in full MS mode ( $2 \mu s c a n s)$ from 60 to $900 \mathrm{~m} / \mathrm{z}$ at 70,000 resolution, with $4 \mathrm{kV}$ spray voltage, 45 sheath gas, and 15 auxiliary gas. Calibration was performed prior to analysis using the Pierce ${ }^{\mathrm{TM}}$ Positive and Negative Ion Calibration Solutions (Thermo Fisher Scientific, Waltham, MA, USA). Acquired data was then converted from raw to mzXML file format using Mass Matrix (Cleveland, OH, USA). Samples were analyzed in randomized order with a technical mixture injected after every 15 samples to qualify instrument performance. Metabolite assignments were performed using MAVEN (Princeton, NJ, USA), [47] against an in-house library of stable isotope-labeled standards [41].

\subsubsection{Proteomics Analyses}

Mouse RBC proteomics analyses were performed via filter-aided sample preparation (FASP), followed by trypsinization and nanoUHPLC-MS/MS analyses (nanoEasy LC II coupeld to QExactive HF, Thermo Fisher), as extensively described in prior work [13]. In the interest of space, the interested reader is referred to previous methods papers from our group for extensive details about the analytical workflow [48].

\subsubsection{Statistical Analysis}

Significance was determined through an ANOVA test (Microsoft Excel, Redmond, CA, USA; GraphPad Prism 5.0, Prism, San Diego, CA, USA) for RBC metabolomics analyses as a function of mouse age or parabiosis. Multivariate analyses, including partial least squares discriminant analysis (PLS-DA), hierarchical clustering analyses, and heat maps, were performed with the software MetaboAnalyst 4.0 [49]. 


\section{Results}

3.1. RBCs from Aging Mice Are Characterized by Significant Proteome-Wide and Metabolic Changes in Antioxidant Systems

Metabolomics analyses were performed on RBCs from six-, 15-, or 25-month-old mice (Figure 1A). Raw data are presented in Table S1 (Supplementary Materials). Multivariate analyses revealed significant differences across samples from mice at different age groups, with aging explaining the majority of total variance (23.4\% in principal component 1 ) in PLS-DA (Figure 1B). Hierarchical clustering analysis (Figure 1C) revealed a significant mouse age-dependent decay in RBC metabolites involved in one-carbon metabolism (e.g., dimethylglycine), carboxylic acids (2-oxoglutarate, succinate), glutathione metabolism (glutamyl-alanine, glutathione), and purine metabolism (urate, 5-hydroxyisourate). Conversely, RBCs from aged mice were characterized by increases in metabolites in the glutathione oxidation and turnover (glutathionyl-cysteine, 5-oxoproline), tryptophan and tyrosine metabolism, glycolytic metabolites (glucose 6-phosphate, phosphoglycerate isomers, phosphoenolpyruvate, 2,3-biphosphoglycerate), one-carbon and choline metabolism (methenyl-tetrahydrofolate (THF), choline, acetylcholine; Figure 1C). Proteomics analyses showed that these metabolic changes were accompanied by progressive age-related decreases in RBC levels of antioxidant enzymes (e.g., glucose 6-phosphate dehydrogenase (G6PDx)), cytosolic isoforms of Krebs cycle enzymes (malate dehydrogenase 1 (MDH1); Figure 1D). On the other hand, increases were observed in the levels of other enzymes including some involved in glycolysis (enolase (ENO1)), glutathione or NADPH-dependent antioxidant enzymes (Gpx1, catalase (Cat), aldehyde dehydrogenase 9 family member 1 (ALDH9A1), biliverdin reductase B (BLVRB), phosphogluconate dehydrogenase (PGD)), proteasome subunits (Psma1, 6, 7; Psmb2; Psmc5; Psmd3; Psme1), and heat-shock proteins (Hspa1b, Hspa5) (Figure 1E). Of note, RBCs from aging mice were characterized by increasing levels of apoptotic markers (Clusterin (Clu); Fatty Acid Synthase (Fasn), complement components (C5, Cfh) and immunoglobulin chains (Ighm, Jchain), phosphatase/kinase system (adducin (Add2); 14-3-3 protein zeta/delta - Ywhaz) and, most notably, markers of organismal aging (Park7, pregnancy zone protein (Pgzp1)). Correlation analysis between protein levels and mouse age revealed top protein correlates (F) and significantly up- and downregulated pathways in aging mouse RBCs (G).

\subsection{Focus on the RBC Metabolic Pathways Impacted by Mouse Age}

\subsubsection{Glutathione, One-Carbon, Glycolysis, and Pentose Phosphate Pathway}

In Figures 2-4, we provide an overview of the top metabolic pathways that were found to be significantly impacted by mouse age from the pathway analysis of proteomics data (Figure 1G) and multivariate analysis of metabolomics data (Figure 1B,C). Specifically, we noted that aging mouse RBCs were characterized by progressive declines of methionine, choline, and dimethylglycine (one-carbon metabolism; Figure 2). These changes were accompanied by glutamine consumption to generate glutamate, glutathione consumption as a result of increases in glutathionyl-cysteine (a marker of glutathione oxidation), and 5-oxoproline (a marker of glutathione turnover) (Figure 2). Conversely, RBC oxidized glutathione (GSSG) levels did not decline with mouse aging, resulting in GSSG/reduced glutathione (GSH) ratios increasing in older mice in comparison to young mice (Figure 2). Changes in redox homeostasis were accompanied by increased glucose consumption, as a result of (i) alterations in pentose phosphate pathway activation (higher ribose phosphate but lower sedoheptulose phosphate as a function of mouse aging), and (ii) increases in early glycolytic intermediates (hexose phosphates and triose phosphate compounds until phosphoenolpyruvate) and decreases in pyruvate and lactate (Figure 2). 
A

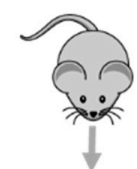

6 months

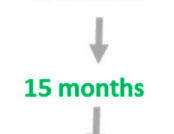

25 months

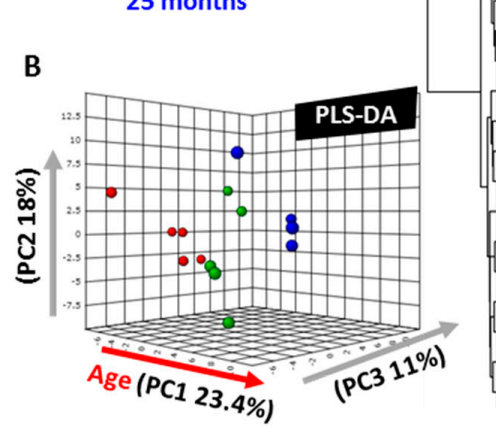

D

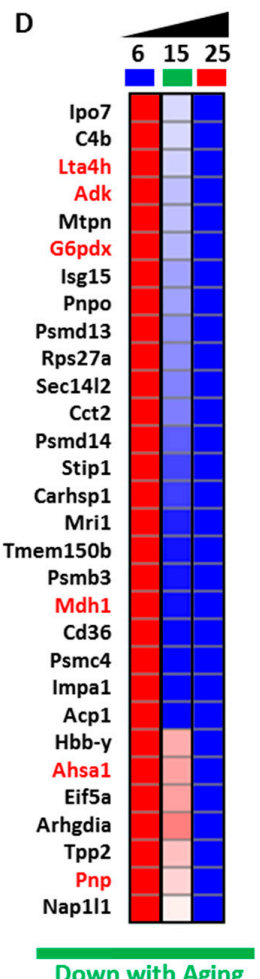

Down with Aging
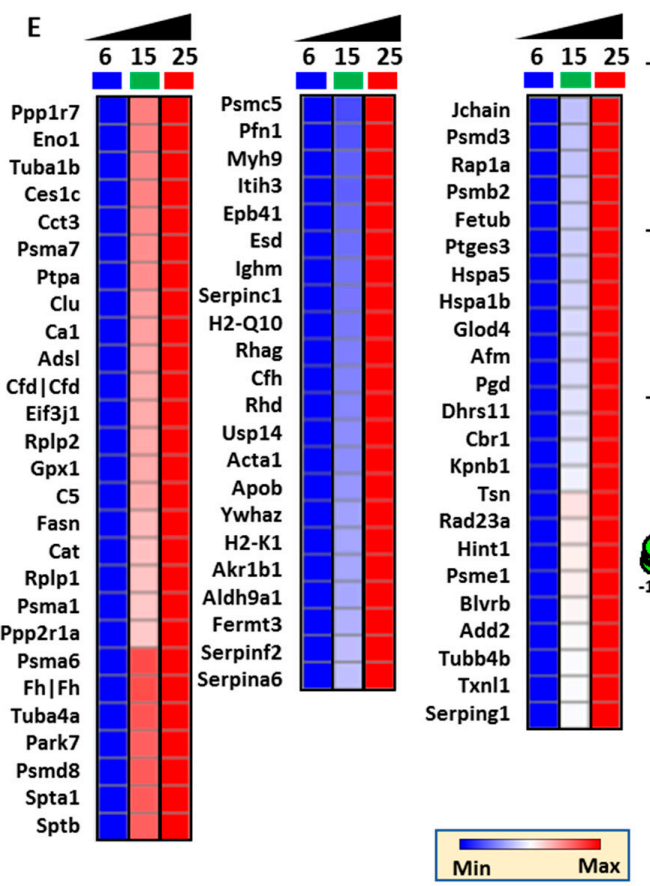

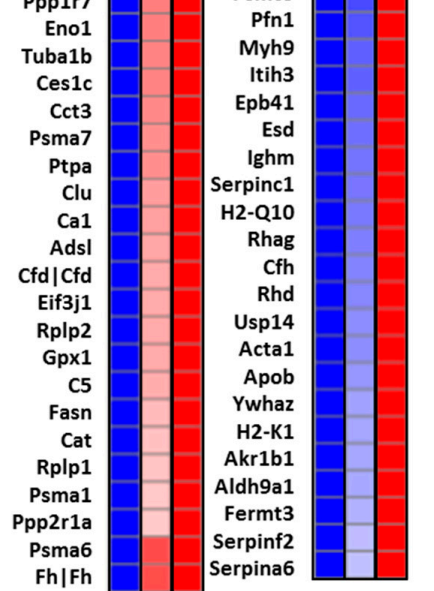

Spta1

Sptb

$$
\text { max }
$$

25 months

Dimethylglycine 5-Hydroxyisourate

2-Oxoglutarate

Urate

Succinate

Indoxyl

Y-Glutamyl-alanine

Pantetheine

Hydroxy-proline

Spermidine

Nicotinamide

GDP

Glutathionyl-cysteine

L-glutamate

5-Oxoproline

3-methyldioxyindole

5-10-MethenyITHF

Choline

Acetylcholine

L-aspartate

Glucose 6-phosphate

Dopamine

2/3-Phospho-glycerate

Phosphoenolpyruvate

2,3-Bisphosphoglycerate

\section{F}

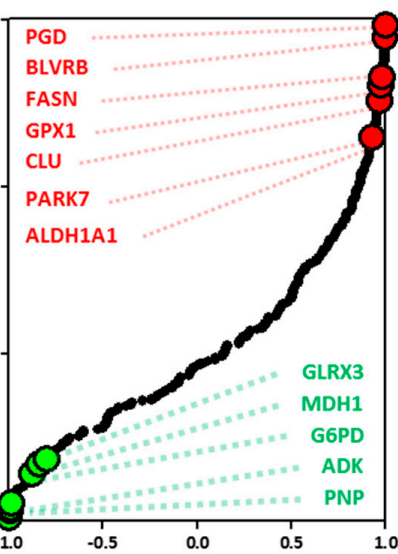

G Correlation with age
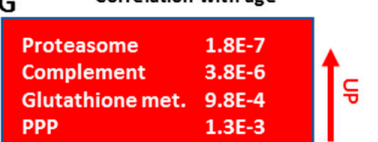

PPP

Metabolic pathways $4.2 \mathrm{E}-2$

Up with Aging

Figure 1. Metabolomics and proteomics of red blood cells (RBCs) from aging mice (six, 15, or 25 months old). (A) An overview of the experimental design. (B) Partial least squares discriminant analysis (PLS-DA) reveals a significant impact of mouse age on RBC metabolic phenotypes, as highlighted by the top 25 significant metabolites by ANOVA in the heat map in (C). Similarly, the RBC proteome was significantly impacted by the age of the animal, with a number of proteins decreasing (D) or increasing (E) with aging. Correlation analysis reveals top protein correlates (F) and significantly upand downregulated pathways in aging mouse RBCs (G). 


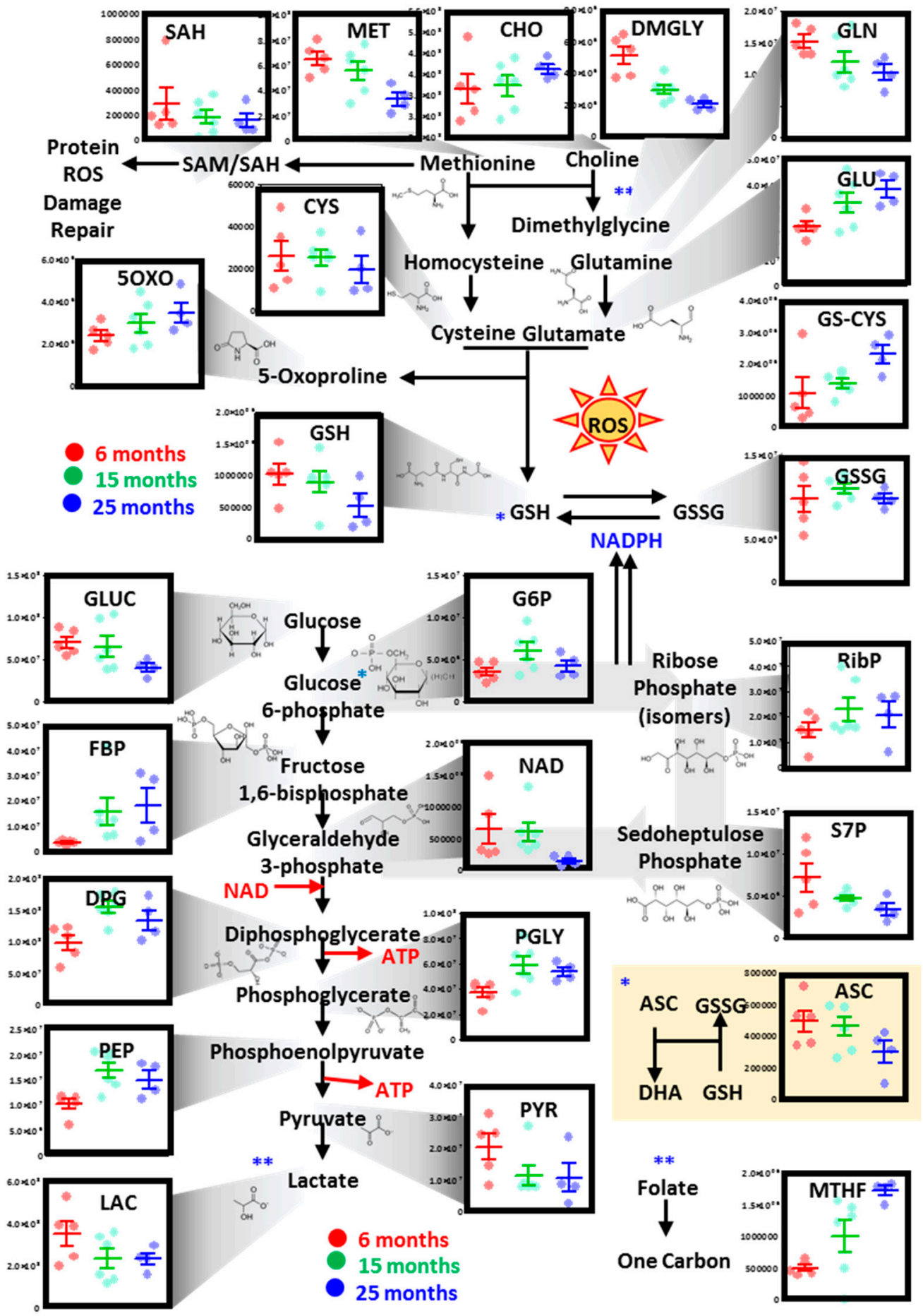

Figure 2. Alterations of RBC glycolysis, the pentose phosphate pathway, and glutathione and one-carbon metabolism as a function of the age of the mouse. Dots represent distinct biological replicates for six(red), 15- (green), and 25-month-old mice (blue). * cross-talk between glutathione homeostasis and glyoxylate pathway. ${ }^{* *}$ cross-talk between methionine and one-carbon metabolism. 

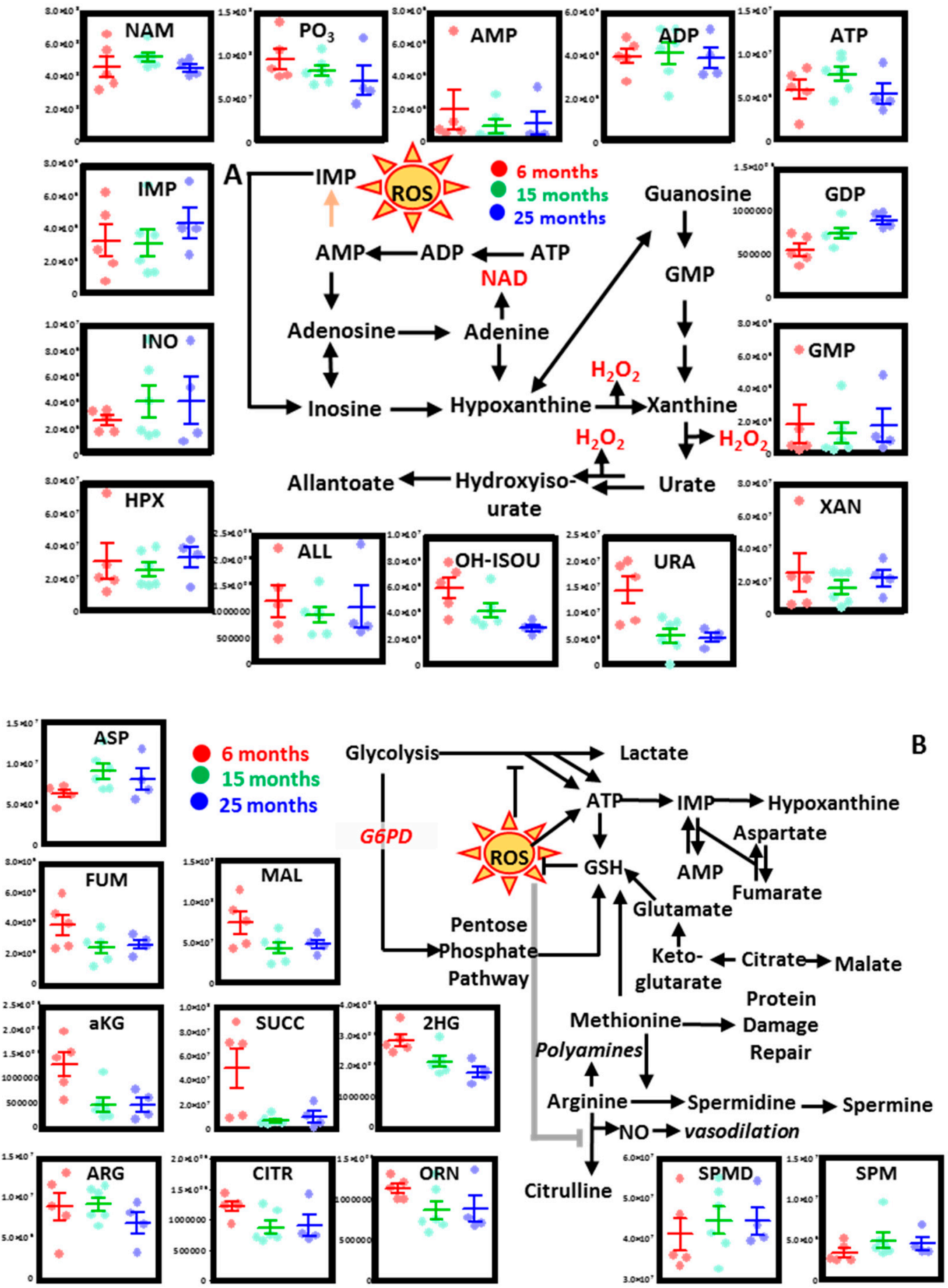

Figure 3. Alterations of purine metabolism (A), and carboxylic acid and arginine metabolism (B) in mouse RBCs as a function of aging. Dots represent distinct biological replicates for six- (red), 15- (green), and 25-month-old mice (blue). 


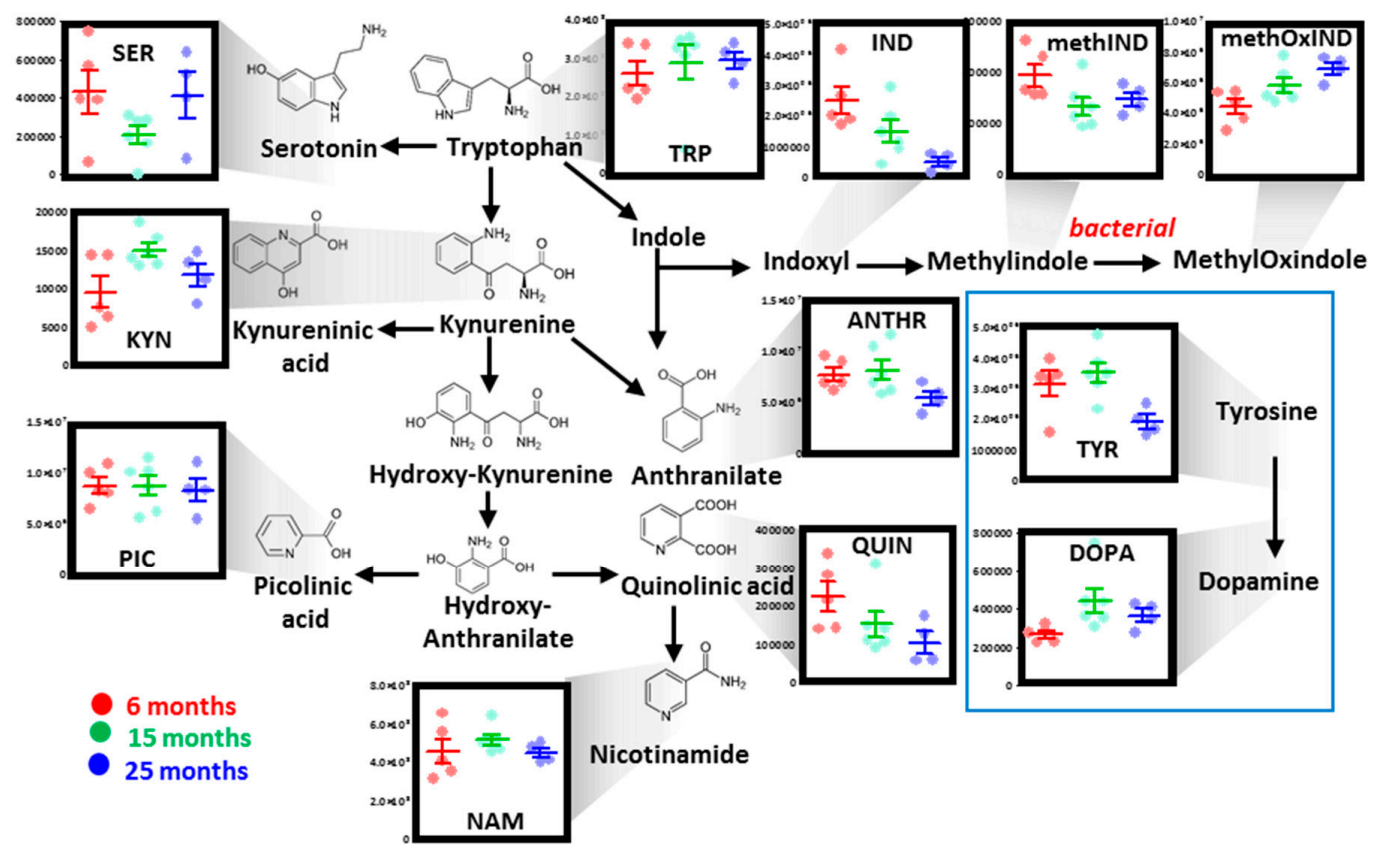

Figure 4. Tryptophan metabolism in mouse RBCs as a function of aging. Dots represent distinct biological replicates for six- (red), 15- (green), and 25-month-old mice (blue).

\subsubsection{Purine Metabolism}

No major changes were observed in aging mouse RBCs with respect to the total adenylate pool (ATP, ADP, AMP), although trends toward decrease were noted for AMP and ATP, especially in the oldest mice. On the other hand, significant increases in GDP, but not GMP, were observed in older mouse RBCs (Figure 3A). Purine catabolism products, including inosine monophosphate (IMP) and its breakdown and oxidation products (inosine, hypoxanthine), were higher in older mice. On the other hand, the final products of the pathway-urate, hydroxyisourate, and allantoate-were either higher in young mouse RBCs or did not change in aging mice (Figure $3 \mathrm{~A}$ ).

\subsubsection{Transamination, Carboxylic Acids, and Arginine Metabolism}

Increases in aspartate and glutamate and decreases in alpha-ketoglutarate (aKG) are suggestive of deregulation of transamination reaction as a function of mouse age (Figure 3B). Since these reactions could be coupled to salvage of purine oxidation, it was interesting to note that carboxylates all decreased in mouse RBCs as a function of age (e.g., aKG, succinate, 2-hydroxyglutarate, fumarate, malate; Figure 3B). Finally, both 15- and 25-month-old mice were characterized by deregulation of arginine metabolism, which resulted in lower levels of citrulline and ornithine, but higher levels of spermidine and spermine in RBCs from old mice (Figure 3B).

\subsubsection{Tryptophan, Tyrosine, and Indole Metabolism}

Multivariate analysis highlighted significant age-related changes in the levels of RBC metabolites of tryptophan and indoles, with kynurenic acid and quinolinic acid increasing and decreasing, respectively as a function of mouse age (Figure 4). Indole metabolites-likely products of bacterial origin-were found to decrease and increase in aged mouse RBCs (Figure 4). Finally, tyrosine decreases in 25-month-old mice were accompanied by significant increases in the levels of its byproduct dopamine (Figure 4).

\subsubsection{Parabiosis Only Partially Restores Metabolic and Proteome-Wide Defects in RBCs from Aging Mice}

After appreciating proteomics and metabolic changes in RBCs from aging mice, we questioned whether some of these age-related phenotypic changes could be reversed by physically connecting the 
circulatory systems of young and old mice-a practice referred to as parabiosis [36]. In the present study, the circulatory systems of two young or old mice (isochronic $\mathrm{Y}-\mathrm{Y}$ or $\mathrm{O}-\mathrm{O}$, respectively) or one young and one old mouse (heterochronic $\mathrm{Y}-\mathrm{O}$ ) were surgically connected (Figure 5A), prior to blood collection from either mouse and subsequent metabolomics (Supplementary Table S2) and proteomics (Supplementary Table S3) analyses. In heterochronic mice, RBCs were either drawn from the young ( $\mathrm{Y}-\mathrm{O} \mathrm{Y})$ or the old $(\mathrm{Y}-\mathrm{O} \mathrm{O})$ mouse. Once again, metabolomics data clearly indicated an impact of mouse age across principal component 1 (PC1; $21.1 \%$ of the total variance). On the other hand, $\mathrm{PC} 2$ and PC 3 accounted for $17.4 \%$ and $6.9 \%$ of the total variance, respectively, mostly as a result of biological variability across mice (PC1) and the effect of parabiosis (PC3) (Figure 5B). Hierarchical clustering of the top 25 metabolites by ANOVA is shown in Figure 5C. Results confirmed a significant impact of aging on glutathione homeostasis, glycolysis, and the pentose phosphate pathway. Only a subgroup of age-related changes were reversed in heterochronic mice, when compared to isochronic old-old mice. Similarly, the proteomes of RBCs from heterochronic mice (young-old mice) were characterized by higher levels of antioxidant enzymes (superoxide dismutase 1 - Sod1) and Cd47, a "do not eat me signal" that prevents the untimely removal of the RBC from the bloodstream via phagocytosis (Figure 5D). Parabiosis also resulted in increased levels of G6PD in the RBC from young-old mice, especially in $\mathrm{Y}-\mathrm{O}$ Y mice (Figure 5D). Heterochronic mice (both $\mathrm{Y}-\mathrm{O} \mathrm{O}$ and $\mathrm{Y}-\mathrm{O} \mathrm{Y}$ ) had young levels of hydroxymethylbilane synthase (HMBS), an enzyme critical in heme metabolism whose mutation is associated with acute porphyrias (Figure 5D). Similarly, heterochronic parabionts had normal levels of NSFL1 cofactor p47 (NSFL1C), a competitive inhibitor of cathepsin proteases [50].

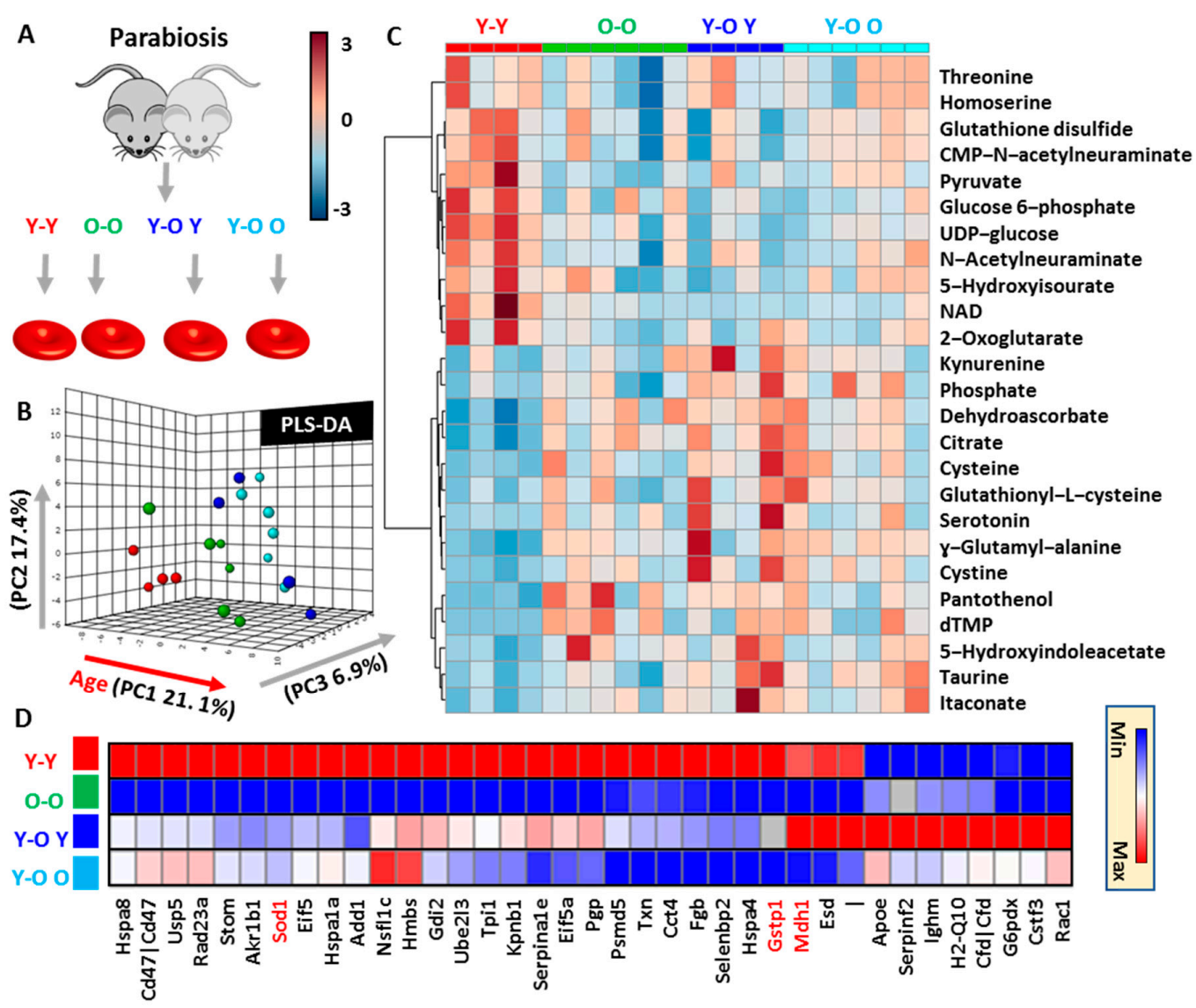

Figure 5. Metabolomics and proteomics analyses of RBCs in isochronic and heterochronic parabiotic mice. In (A), an overview of the experimental design. In (B), partial least square-discriminant analysis (PLS-DA) from the metabolomics data. In (C,D), top significant metabolic and protein changes in the parabiosis experiments are presented in the form of a heat map. 


\subsubsection{Parabiosis Only Partial Rescues the Age-Dependent Changes in RBC Metabolism}

Parabiosis partially corrected the metabolic defect in one-carbon metabolism, by normalizing the levels of methionine and increasing RBC levels of choline (Figure 6). However, age-dependent decreases in S-adenosylmethionine (SAM) and dimethylglycine were aggravated in Y-O mice (Figure 6). Similar increases were observed in $\mathrm{Y}-\mathrm{O}$ mice with respect to cysteine and glutathionyl-cysteine, despite an apparent normalization of the levels of reduced, but not oxidized glutathione in comparison to $\mathrm{O}-\mathrm{O}$ mice (Figure 6). Levels of 5-oxoproline were decreased, while ribose phosphate increased in $\mathrm{O}-\mathrm{O}$ and $\mathrm{Y}-\mathrm{O}$ mice (Figure 6), a trend inconsistent with that observed in RBCs from aging mice (Figure 2), likely as a confounding effect of the surgical practice of parabiosis. On the other hand, parabiosis decreased the levels of early glycolytic metabolites and partially normalized the levels of late glycolytic products pyruvate and lactate back to young mouse RBC levels (Figure 6). Perhaps the most striking finding in parabiotic mice was that RBC levels of NAD dropped significantly in old mouse RBCs and were not improved by parabiosis.

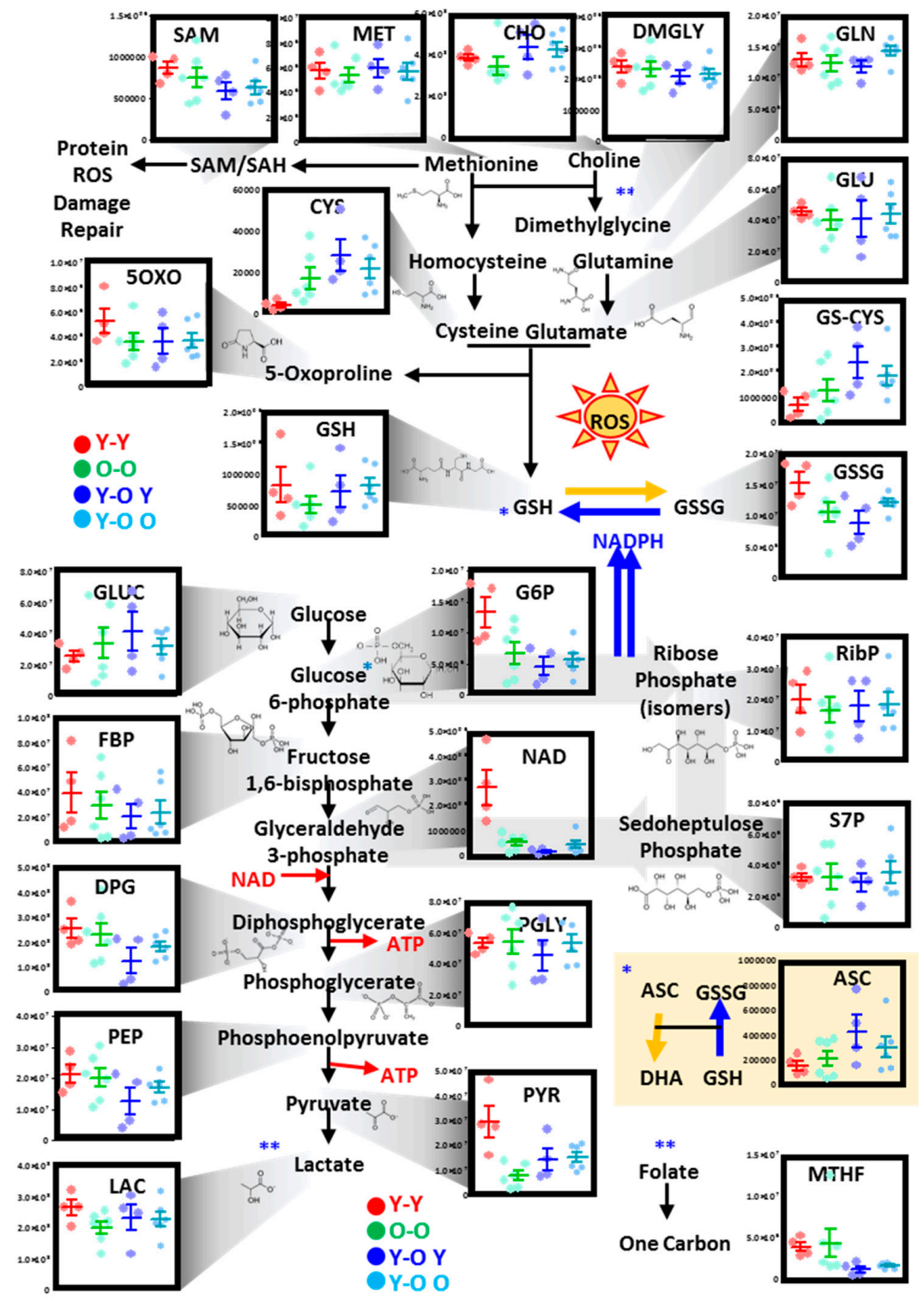

Figure 6. Alterations of RBC glycolysis, the pentose phosphate pathway, and glutathione and one-carbon metabolism in isochronic and heterochronic parabiotic mice. Dots represent distinct biological replicates for isochronic young ( $\mathrm{Y}$ )-young (red) or old (O)-old (green), or heterochronic $\mathrm{Y}-\mathrm{O}$ mice with blood being drawn from the young mouse (blue) or the old mouse (light blue). * cross-talk between glutathione homeostasis and glyoxylate pathway. ${ }^{* *}$ cross-talk between methionine and one-carbon metabolism. 
Age-related changes in parabiotic mouse RBC purines mostly confirmed and in part expanded the observation from aging mice (Figure 7A). In particular, in this set of experiments, RBCs from $\mathrm{O}-\mathrm{O}$ parabiotic mice had lower levels of high-energy phosphate purines (ATP and ADP), a trend that was not reversed by parabiosis in heterochronic mice. On the other hand, parabiosis seemed to aggravate age-associated purine oxidation from urate/5-hydroxyisourate to allantoin (Figure 7A). Similar considerations can be made for the RBC levels of carboxylic acids (especially fumarate, malate, and aKG), polyamines, and creatine (arginine metabolite) (Figure 7B). Finally, RBC levels of tryptophan and indole metabolites increased in $\mathrm{O}-\mathrm{O}$ compared to $\mathrm{Y}-\mathrm{Y}$ mice, a trend that was further exacerbated in heterochronic mice, with the exception of the neurotoxic picolinic acid and NAD-precursor nicotinamide (Figure 8).
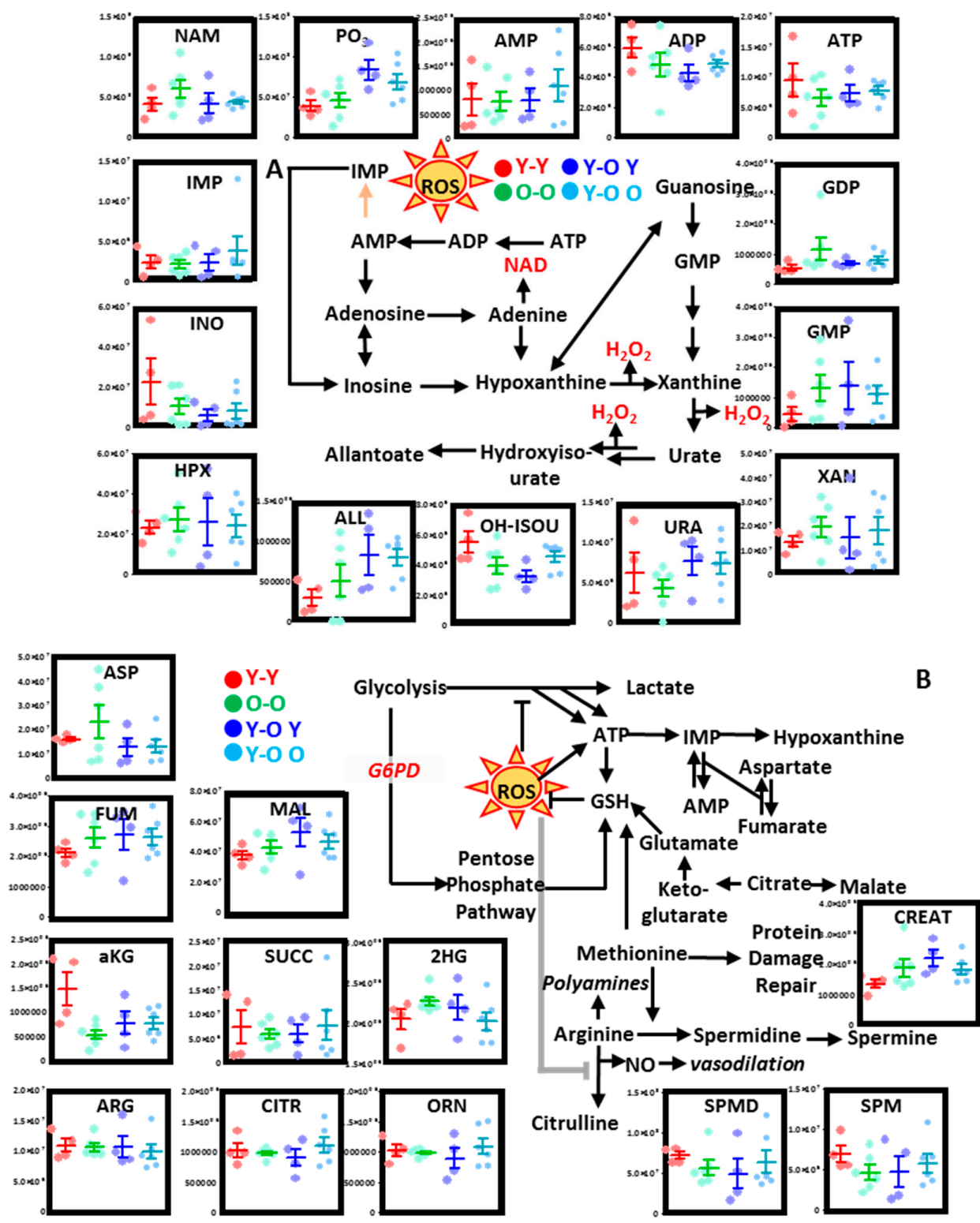

Figure 7. Alterations of RBC purine metabolism (A), and carboxylic acid and arginine metabolism (B) in isochronic and heterochronic parabiotic mice. Dots represent distinct biological replicates for isochronic young-young (red) or old-old (green), or heterochronic $\mathrm{Y}-\mathrm{O}$ mice with blood being drawn from the young mouse (blue) or the old mouse (light blue). 


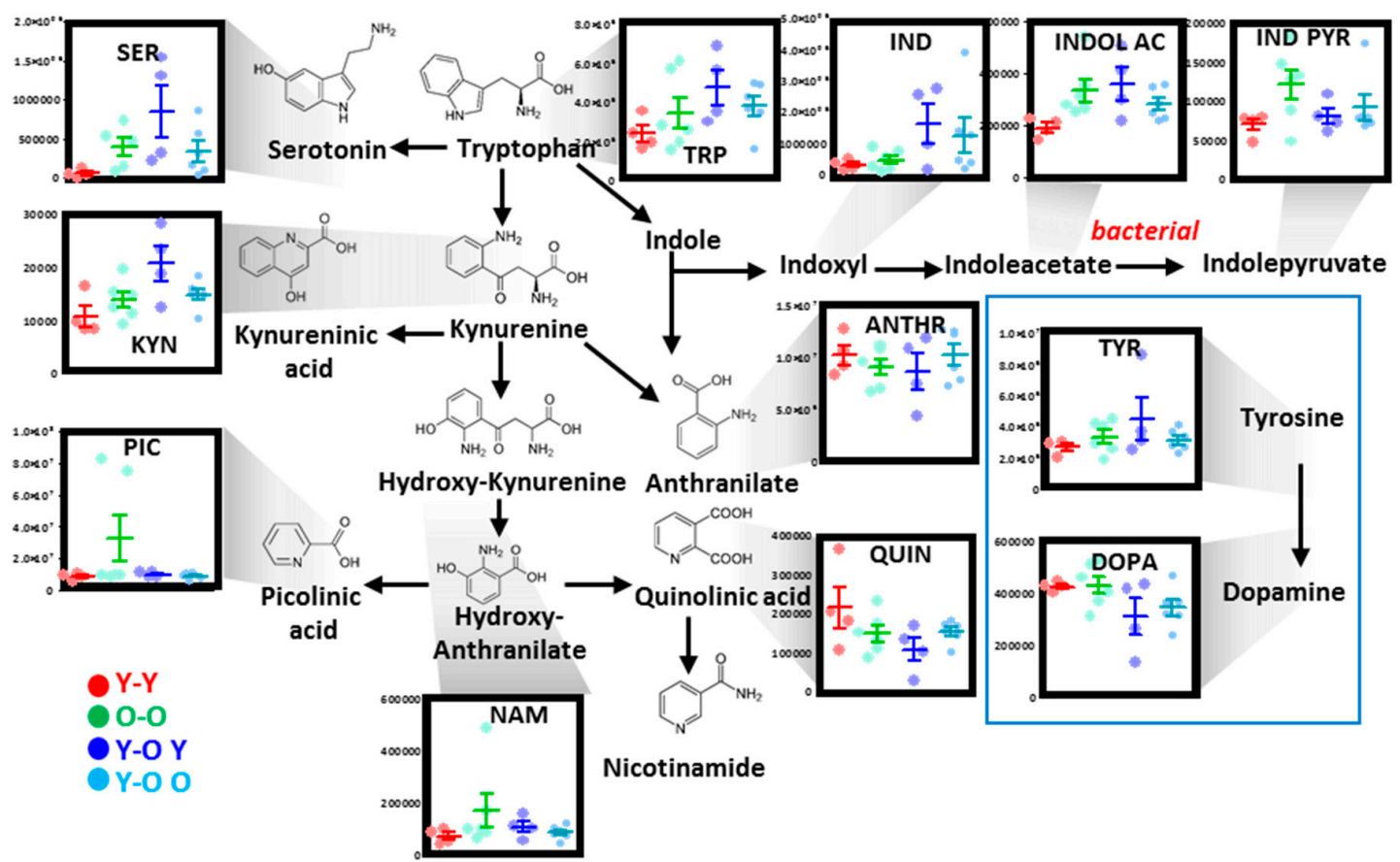

Figure 8. Alterations of RBC tryptophan metabolism in isochronic and heterochronic parabiotic mice. Dots represent distinct biological replicates for isochronic young-young (red) or old-old (green), or heterochronic $\mathrm{Y}-\mathrm{O}$ mice with blood being drawn from the young mouse (blue) or the old mouse (light blue).

\section{Discussion}

In the present study, we analyzed the metabolome and proteome of RBCs from aging mice. Expectedly, we found that RBC antioxidant capacity declined as a function of mouse age, a phenomenon that was in part warranted by progressive declines in glutathione pools, in part by deregulated PPP at the protein (G6PD) and metabolic level. Prior work from the late 1970s/early 1980s showed age-dependent declines in G6PD activity [20,22] and glutathione pools [19-21]. The results are consistent with classic literature and recent observations in RBCs from Down syndrome [30] and non-trisomic subjects [29]. Expanding on the literature, we report that dysregulation of glutathione metabolism was in part explained by increases in oxidation and turnover of glutathione, with 5-oxoproline representing a metabolic bottleneck in RBCs owing to the lack of a functional oxoprolinase [51]. Increased glutaminolysis and glutamate/aspartate levels in the face of higher levels of cysteine were detected in the erythrocytes of aging mice, a phenotype consistent with decreased glutathione synthesis [52,53] and dysregulated transamination (also manifesting in low levels of aKG in RBCs from 15- and 25-month-old mice). Since glutathione synthesis is an ATP-dependent process, it was interesting to note that the total ATP pool was decreased in RBCs from isochronic $\mathrm{O}-\mathrm{O}$ parabiotic mice, with trending decreases of ATP and AMP in RBCs from aging, non-parabiotic mice. Decreases in late glycolysis were noted despite an apparent rerouting of glucose moieties toward glycolysis, as apparent by the accumulation of early glycolytic intermediates. A tentative explanation is due to potential decreases in glucose uptake (as intracellular glucose levels declined as a function of mouse age), since the glucose transporter (Solute Carrier Family 2 Member 1-SLC2A1) was reported to be controlled transcriptionally (at earlier erythropoietic stages) by redox sensing transcriptional regulators such as ataxia-telangiencatasia mutated (ATM) [54], which also regulates G6PD at the transcriptional level [55]. On the other hand, it was shown in other systems that late glycolytic enzymes such as pyruvate kinase-where a metabolic bottleneck was observed in RBCs from old mice in the present study - can be regulated via the mechanism of redox-regulated glutathionylation [56]. However, in the present study, no significant age-dependent increase in pyruvate kinase glutathionylation was observed in old mouse RBCs, which were instead characterized by progressive oxidation and higher levels of glutathionylation of cysteine 94 of hemoglobin beta (data 
not shown)—one of the main redox-sensitive cysteines in RBCs [57,58]. An alternative explanation of this apparent blockade in late glycolysis is that other redox-sensitive thiols (e.g., Cys152 and 156 of glyceraldehyde 3-phosphate dehydrogenase [59]) could be oxidized in RBCs as a function of aging, although proteomics data did not confirm that in this study.

Alternatively, mouse aging may result in the depletion of cofactors that are essential to sustain glycolysis, such as nicotinamide adenine dinucleotide (NAD). Notably, NAD levels decreased with mouse age and were the lowest in 25-month-old mice, a phenotype that was not corrected by parabiosis. This is interesting owing to the increasingly appreciated link between aging and NAD depletion [60-63], an observation that fueled the industry of supplements based on NAD precursors. Even more intriguingly, NAD is a downstream product of tryptophan metabolism, a pathway that is significantly impacted by aging and inflammation [64,65]. In Down syndrome, increased tryptophan oxidation as a function of interferon-induced indole 2,3-dioxygenase (IDO1) activity results in the accumulation of neurotoxic metabolites like kynurenine and picolinic acid [66], potential contributors to the neurocognitive decline observed in the Down syndrome population [30,35] and, in general, during aging. While parabiosis had arguably little to no effect on most metabolic pathways, it is worthwhile to note that RBC levels of picolinic and quinolinic acid, but not kynurenic acid, were normalized in heterochronic parabiotic mice. Of note, the tryptophan/kynurenine axis was recently associated with a relay axis that regulates arginine catabolism to polyamines as a function of IDO1 and arginase 1 activity in dendritic cells [34], an observation that is herein phenocopied in RBCs from aging mice and only partially normalized by parabiosis.

Recent studies highlighted the potential role as signaling molecules of tryptophan-derived indoles, metabolites that can be generated by some Gram-negative bacteria in the gut microbiome $[64,67,68]$. Although merely speculative at this stage, it is interesting to note that indole metabolites were significantly impacted by the age of the animal in RBCs, which also circulate in microcapillaries in the gut and are, thus, indirectly exposed to bacterial metabolites. As such, the observed changes in metabolites of potential bacterial origin in aged mouse RBCs could represent a previously unappreciated marker of gut dysbiosis in "inflammaging" that warrants further investigation in the future.

Increases in circulating levels of pro-inflammatory cytokines such as interleukin-1 (IL-1) and -18 were proposed as mediators of the aging process [69]. Increases in circulating levels of IL-1 $\beta$ were shown to skew hematopoiesis toward the myeloid lineage by mechanisms involving the activation of a PU.1-dependent gene program [17]. This mechanism could potentially explain the phenomenon of "anemia in the elderly" [70], a condition that is found in $~ 80 \%$ of elderly patients and at least in part explained by progressive iron, folate, and vitamin B12 deficiency [18]. Of note, both folate and vitamin B12 are essential players in one-carbon metabolism, a pathway that fuels the synthesis of purines and S-adenosylmethionine for protein, DNA, and RNA methylation purposes. Indeed, dietary manipulation of folates results in altered hematopoiesis [71], and dysregulation of this pathway owing to dosage increase of cystathionine beta synthase in Down syndrome results in macrocytic anemia and homocystinuria [72]. Notably, in the present study, one-carbon metabolism (including critical players methionine, choline, dimethylglycine, and methenyl-THF) was the most dysregulated pathway in the aged mouse RBC. This is particularly relevant in RBCs, since increased methionine consumption is critical to the RBC capacity to repair isoaspartyl damage to proteins as a function of oxidant stress by mechanisms involving the protein L-isoaspartyl methyltransferase (PIMT1) [33,40]. Indeed, genetic ablation of PIMT1 results in $100 \%$ mortality by $6-8$ weeks of age because of seizures following unsustainable oxidant damage to the central nervous system [73-76]. In this view, it is interesting to note that (i) parabiosis was previously shown to correct, at least in part, the neurocognitive defect in the aging mouse [37], and that (ii) in the present study, parabiosis effectively replenished the RBC levels of methyl-group donors methionine and choline, although it was insufficient to fully normalize one-carbon metabolism in the heterochronic mouse RBC. Overall, in the context of the literature and the data presented herein, further studies investigating the potential linkage between $\mathrm{RBC}$ one-carbon metabolism, oxidant stress, and protein damage repair in aging seem appropriate. 
Anemia in the elderly is associated with a compromised capacity to sustain sufficient tissue hypoxia. Of note, RBC levels of carboxylic acids were previously associated with high-altitude [77] or hemorrhagic hypoxia [78], while circulating levels of carboxylic acids are indicators of pathological mitochondrial dysfunction in aging, trauma, and inflammation [79-82]. In this study, RBC levels of carboxylic acids were significantly decreased as a function of mouse age. However, a limitation of our analysis and its interpretation is that plasma samples were not available to determine matching levels of these metabolites. Still, the appreciation of significantly lower levels of cytosolic isoforms of Krebs cycle enzymes such as MDH1 is consistent with altered NAD/NADP-dependent metabolism [83] in the RBC from the aged mouse. In the mature RBC, these alterations manifest themselves as a result of the dysregulation of redox-regulated pathways related to purine oxidation and salvage [44], a phenomenon that was observed in the RBC of the aged mouse, which negatively impacted the total adenylate pool and, thus, the energy status of the cell, independently of parabiosis.

RBCs from old mice were characterized by higher levels of proteasome subunits and cellular senescence signaling components (clusterin [84]), suggestive of potential compensatory mechanisms to cope with increased oxidant stress in the face of decreased G6PD levels and PPP activation.

Recently, debate sparked over the opportunity to "rejuvenate" old subjects by transfusion of blood from young donors [85-87]. Commercial companies jumped on the opportunity to leverage a well-established medical practice to profit on a potentially game-changing therapy for aging. However, recent critical reassessment of currently available literature by the Food and Drug Administration "cautions consumers against receiving young donor plasma infusions that are promoted as unproven treatment for varying conditions" at this stage [88]. In this context, it is worthwhile to note that the present study did not focus on the potential impact of transfusion of blood from young mice into old mice; rather, it tested the impact of heterochronic parabiosis in the context of aging. As such, caveats should be acknowledged such as the likely biological impact of the parabiosis procedure per se on mouse RBCs. Finally, it should be noted that transfusion of young mouse RBCs into old mice would represent an "acute" procedure, while parabiotic mice were surgically connected for $\sim 2$ months. In this view, making our report represents an assessment of the impact of a "chronic" procedure/phenotype; thus, any parallelism to the potential impact of transfusion of young blood into old subjects would be merely speculative.

\section{Conclusions}

In the present study, we report the results from metabolomics and proteomics analyses of RBCs from six-, 15-, and 25-month-old mice. As a result, we identified a significant decline in the glutathione and NADPH-dependent antioxidant capacity of the RBCs from aged mice. This phenomenon was accompanied by declines in one-carbon metabolism, and increased purine and tryptophan oxidation, with the latter being associated with significant decreases in the NAD pool. Parabiosis experiments were performed to investigate whether circulation in the bloodstream of a younger mouse was sufficient to restore the metabolic phenotype of an RBC from an old mouse into a younger phenotype. However, parabiosis only partially rescued the alterations in one-carbon metabolism, although it had minimal to no impact on glutathione homeostasis, the PPP, and oxidation of purines and tryptophan, which were instead aggravated in heterochronic parabiotic mice. Compensatory mechanisms seemed to emerge in the RBC from aged mice, such as increased utilization of one-carbon compounds from methyl-group donors, and increased levels of proteasomal and apoptotic cascade components in the mature RBC from aged mice when compared to their counterparts from younger mice. Future studies will be necessary to mechanistically expand on the present observations, such as investigations aimed at defining (i) the role of G6PD activity (or lack thereof) in the mature RBC as a function of aging, (ii) the role of these potential compensatory mechanisms involving the use of one-carbon moieties, proteasome activation, or cellular senescence cascades in the aging organism, and, most importantly, (iii) whether and to what extent these critical players of RBC redox and energy homeostasis contribute to aging-associated comorbidities. 
Supplementary Materials: The following are available online at http://www.mdpi.com/2072-6643/11/6/1337/s1: Table S1: Metabolomics report for aging mouse RBCs; Table S2: Metabolomics report for parabiotic mouse RBCs; Table S3: Proteomics report for aging and parabiotic mouse RBCs.

Author Contributions: L.S., F.G., and D.M.H. generated the aging and parabiotic mouse RBC samples. E.J.M., D.P.C. and T.N. performed metabolomics extractions and data analyses. M.D. and K.C.H. performed proteomics analyses. E.J.M. and A.D. prepared the figures. A.D. and J.C.Z. wrote the first draft of the manuscript, and all authors critically contributed to its finalization.

Funding: Research reported in this publication was funded by the Boettcher Webb-Waring Investigator Award (A.D.) and a Shared Instrument grant by the National Institute of Health to K.C.H. (S10OD021641) and the Einstein Nathan Shock Center for Excellence in the Biology of Aging (P30AG038072).

Conflicts of Interest: Although unrelated to the contents of this manuscripts, the authors declare that A.D. and K.C.H. are founders of Omix Technologies Inc and Altis Biosciencens LLC. A.D. is a consultant for Hemanext Inc. All the other authors disclose no conflicts of interest relevant to this study.

\section{References}

1. Christensen, K.; Doblhammer, G.; Rau, R.; Vaupel, J.W. Ageing populations: The challenges ahead. Lancet (Lond. Engl.) 2009, 374, 1196-1208. [CrossRef]

2. Bloom, D.E.; Chatterji, S.; Kowal, P.; Lloyd-Sherlock, P.; McKee, M.; Rechel, B.; Rosenberg, L.; Smith, J.P. Macroeconomic implications of population ageing and selected policy responses. Lancet (Lond. Engl.) 2015, 385, 649-657. [CrossRef]

3. Balasubramanian, P.; Howell, P.R.; Anderson, R.M. Aging and Caloric Restriction Research: A Biological Perspective with Translational Potential. EBioMedicine 2017, 21, 37-44. [CrossRef] [PubMed]

4. Eichhorn, G.L. Aging, genetics, and the environment: Potential of errors introduced into genetic information transfer by metal ions. Mech. Ageing Dev. 1979, 9, 291-301. [CrossRef]

5. Rodríguez-Rodero, S.; Fernández-Morera, J.L.; Menéndez-Torre, E.; Calvanese, V.; Fernández, A.F.; Fraga, M.F. Aging Genetics and Aging. Aging Dis. 2011, 2, 186-195.

6. Piper, M.D.W.; Bartke, A. Diet and aging. Cell Metab. 2008, 8, 99-104. [CrossRef] [PubMed]

7. Tanaka, H.; Dinenno, F.A.; Monahan, K.D.; Clevenger, C.M.; DeSouza, C.A.; Seals, D.R. Aging, habitual exercise, and dynamic arterial compliance. Circulation 2000, 102, 1270-1275. [CrossRef]

8. Piperakis, S.M.; Visvardis, E.E.; Sagnou, M.; Tassiou, A.M. Effects of smoking and aging on oxidative DNA damage of human lymphocytes. Carcinogenesis 1998, 19, 695-698. [CrossRef]

9. Cui, H.; Kong, Y.; Zhang, H. Oxidative Stress, Mitochondrial Dysfunction, and Aging. J. Signal Transduct. 2012, 2012. [CrossRef]

10. Romano, A.D.; Serviddio, G.; de Matthaeis, A.; Bellanti, F.; Vendemiale, G. Oxidative stress and aging. J. Nephrol. 2010, 23, S29-S36.

11. Anderson, R.M.; Le Couteur, D.G.; de Cabo, R. Caloric Restriction Research: New Perspectives on the Biology of Aging. J. Gerontol. Ser. A Biol. Sci. Med. Sci. 2018, 73, 1-3. [CrossRef] [PubMed]

12. Nemkov, T.; Reisz, J.A.; Xia, Y.; Zimring, J.C.; D'Alessandro, A. Red blood cells as an organ? How deep omics characterization of the most abundant cell in the human body highlights other systemic metabolic functions beyond oxygen transport. Expert Rev. Proteom. 2018, 15, 855-864. [CrossRef] [PubMed]

13. D'Alessandro, A.; Dzieciatkowska, M.; Nemkov, T.; Hansen, K.C. Red blood cell proteomics update: Is there more to discover? Blood Transfus. 2017, 15, 182-187.

14. Bryk, A.H.; Wiśniewski, J.R. Quantitative Analysis of Human Red Blood Cell Proteome. J. Proteome Res. 2017, 16, 2752-2761. [CrossRef] [PubMed]

15. Bayer, S.B.; Hampton, M.B.; Winterbourn, C.C. Accumulation of oxidized peroxiredoxin 2 in red blood cells and its prevention. Transfusion 2015, 55, 1909-1918. [CrossRef]

16. Franceschi, C.; Garagnani, P.; Parini, P.; Giuliani, C.; Santoro, A. Inflammaging: A new immune-Metabolic viewpoint for age-related diseases. Nat. Rev. Endocrinol. 2018, 1, 576-590. [CrossRef] [PubMed]

17. Pietras, E.M.; Mirantes-Barbeito, C.; Fong, S.; Loeffler, D.; Kovtonyuk, L.V.; Zhang, S.; Lakshminarasimhan, R.; Chin, C.P.; Techner, J.-M.; Will, B.; et al. Chronic interleukin-1 exposure drives haematopoietic stem cells towards precocious myeloid differentiation at the expense of self-renewal. Nat. Cell Biol. 2016, 18, 607-618. [CrossRef] 
18. Goodnough, L.T.; Schrier, S.L. Evaluation and management of anemia in the elderly. Am. J. Hematol. 2014, 89, 88-96. [CrossRef]

19. Abraham, E.C.; Taylor, J.F.; Lang, C.A. Influence of mouse age and erythrocyte age on glutathione metabolism. Biochem. J. 1978, 174, 819-825. [CrossRef]

20. Maurya, P.K.; Kumar, P.; Chandra, P. Age-dependent detection of erythrocytes glucose-6-phosphate dehydrogenase and its correlation with oxidative stress. Arch. Physiol. Biochem. 2016, 122, 61-66. [CrossRef]

21. Magnani, M.; Piatti, E.; Serafini, N.; Palma, F.; Dachà, M.; Fornaini, G. The age-dependent metabolic decline of the red blood cell. Mech. Ageing Dev. 1983, 22, 295-308. [CrossRef]

22. Rodgers, G.P.; Lichtman, H.C.; Sheff, M.F. Red blood cell glucose-6-phosphate dehydrogenase activity in aged humans. J. Am. Geriatr. Soc. 1983, 31, 8-11. [CrossRef]

23. Rinalducci, S.; D’Amici, G.M.; Blasi, B.; Vaglio, S.; Grazzini, G.; Zolla, L. Peroxiredoxin-2 as a candidate biomarker to test oxidative stress levels of stored red blood cells under blood bank conditions. Transfusion 2011, 51, 1439-1449. [CrossRef] [PubMed]

24. Paukovich, N.; Xue, M.; Elder, J.R.; Redzic, J.S.; Blue, A.; Pike, H.; Miller, B.G.; Pitts, T.M.; Pollock, D.D.; Hansen, K.; et al. Biliverdin Reductase B Dynamics Are Coupled to Coenzyme Binding. J. Mol. Biol. 2018, 430, 3234-3250. [CrossRef] [PubMed]

25. Pallotta, V.; Gevi, F.; D'alessandro, A.; Zolla, L. Storing red blood cells with vitamin C and N-acetylcysteine prevents oxidative stress-related lesions: A metabolomics overview. Blood Transfus. 2014, 12, 376-387.

26. Chen, L.; Zhang, Z.; Hoshino, A.; Zheng, H.D.; Morley, M.; Arany, Z.; Rabinowitz, J.D. NADPH production by the oxidative pentose-phosphate pathway supports folate metabolism. Nat. Metab. 2019, 1, 404-415. [CrossRef] [PubMed]

27. Tzounakas, V.L.; Kriebardis, A.G.; Georgatzakou, H.T.; Foudoulaki-Paparizos, L.E.; Dzieciatkowska, M.; Wither, M.J.; Nemkov, T.; Hansen, K.C.; Papassideri, I.S.; D’Alessandro, A.; et al. Glucose 6-phosphate dehydrogenase deficient subjects may be better "storers" than donors of red blood cells. Free Radic. Biol. Med. 2016, 96, 152-165. [CrossRef]

28. Nóbrega-Pereira, S.; Fernandez-Marcos, P.J.; Brioche, T.; Gomez-Cabrera, M.C.; Salvador-Pascual, A.; Flores, J.M.; Viña, J.; Serrano, M. G6PD protects from oxidative damage and improves healthspan in mice. Nat. Commun. 2016, 7, 10894. [CrossRef]

29. Chaleckis, R.; Murakami, I.; Takada, J.; Kondoh, H.; Yanagida, M. Individual variability in human blood metabolites identifies age-related differences. Proc. Natl. Acad. Sci. USA 2016, 113, 4252-4259. [CrossRef]

30. Culp-Hill, R.; Zheng, C.; Reisz, J.A.; Smith, K.; Rachubinski, A.; Nemkov, T.; Butcher, E.; Granrath, R.; Hansen, K.C.; Espinosa, J.M.; et al. Red blood cell metabolism in Down syndrome: Hints on metabolic derangements in aging. Blood Adv. 2017, 1, 2776-2780. [CrossRef]

31. Horvath, S.; Garagnani, P.; Bacalini, M.G.; Pirazzini, C.; Salvioli, S.; Gentilini, D.; Di Blasio, A.M.; Giuliani, C.; Tung, S.; Vinters, H.V.; et al. Accelerated epigenetic aging in Down syndrome. Aging Cell 2015, 14, 491-495. [CrossRef] [PubMed]

32. Kusters, M.A.A.; Verstegen, R.H.J.; de Vries, E. Down Syndrome: Is It Really Characterized by Precocious Immunosenescence? Aging Dis. 2011, 2, 538-545. [PubMed]

33. Galletti, P.; De Bonis, M.L.; Sorrentino, A.; Raimo, M.; D’Angelo, S.; Scala, I.; Andria, G.; D'Aniello, A.; Ingrosso, D.; Zappia, V. Accumulation of altered aspartyl residues in erythrocyte proteins from patients with Down's syndrome. FEBS J. 2007, 274, 5263-5277. [CrossRef] [PubMed]

34. Mondanelli, G.; Bianchi, R.; Pallotta, M.T.; Orabona, C.; Albini, E.; Iacono, A.; Belladonna, M.L.; Vacca, C.; Fallarino, F.; Macchiarulo, A.; et al. A Relay Pathway between Arginine and Tryptophan Metabolism Confers Immunosuppressive Properties on Dendritic Cells. Immunity 2017, 46, 233-244. [CrossRef] [PubMed]

35. Powers, R.K.; Sullivan, K.D.; Culp-Hill, R.; Ludwig, M.P.; Smith, K.P.; Waugh, K.A.; Minter, R.; Tuttle, K.D.; Rachubinski, A.L.; Granrath, R.E.; et al. Trisomy 21 drives production of neurotoxic tryptophan catabolites via the interferon-inducible kynurenine pathway. BioRxiv 2018. [CrossRef]

36. Kamran, P.; Sereti, K.-I.; Zhao, P.; Ali, S.R.; Weissman, I.L.; Ardehali, R. Parabiosis in mice: A detailed protocol. J. Vis. Exp. JoVE 2013, 6. [CrossRef]

37. Gontier, G.; Iyer, M.; Shea, J.M.; Bieri, G.; Wheatley, E.G.; Ramalho-Santos, M.; Villeda, S.A. Tet2 Rescues Age-Related Regenerative Decline and Enhances Cognitive Function in the Adult Mouse Brain. Cell Rep. 2018, 22, 1974-1981. [CrossRef] 
38. Harris, R.B. Loss of body fat in lean parabiotic partners of ob/ob mice. Am. J. Physiol. 1997, 272, R1809-R1815. [CrossRef]

39. Harris, R.B. Parabiosis between $\mathrm{db} / \mathrm{db}$ and $\mathrm{ob} / \mathrm{ob}$ or $\mathrm{db} /+$ mice. Endocrinology 1999, 140, 138-145. [CrossRef]

40. Reisz, J.A.; Nemkov, T.; Dzieciatkowska, M.; Culp-Hill, R.; Stefanoni, D.; Hill, R.C.; Yoshida, T.; Dunham, A.; Kanias, T.; Dumont, L.J.; et al. Methylation of protein aspartates and deamidated asparagines as a function of blood bank storage and oxidative stress in human red blood cells. Transfusion 2018, 58, 2978-2991. [CrossRef]

41. Nemkov, T.; Hansen, K.C.; D'Alessandro, A. A three-minute method for high-throughput quantitative metabolomics and quantitative tracing experiments of central carbon and nitrogen pathways. Rapid Commun. Mass Spectrom. RCM 2017, 31, 663-673. [CrossRef]

42. D'Alessandro, A.; Culp-Hill, R.; Reisz, J.A.; Anderson, M.; Fu, X.; Nemkov, T.; Gehrke, S.; Zheng, C.; Kanias, T.; Guo, Y.; et al. Heterogeneity of blood processing and storage additives in different centers impacts stored Red Blood Cell metabolism as much as storage time: Lessons from REDS-III-Omics. Transfusion 2018, 59, 89-100. [CrossRef] [PubMed]

43. Culp-Hill, R.; Srinivasan, J.; Gehrke, S.; Kamyszek, R.; Ansari, A.; Shah, N.; Welsby, I.; D'Alessandro, A. Effects of red blood cell (RBC) transfusion on sickle cell disease recipient plasma and RBC metabolism. Transfusion 2018, 58, 2797-2806. [CrossRef] [PubMed]

44. Nemkov, T.; Sun, K.; Reisz, J.A.; Song, A.; Yoshida, T.; Dunham, A.; Wither, M.J.; Francis, R.O.; Roach, R.C.; Dzieciatkowska, M.; et al. Hypoxia modulates the purine salvage pathway and decreases red blood cell and supernatant levels of hypoxanthine during refrigerated storage. Haematologica 2018, 103, 361-372. [CrossRef] [PubMed]

45. Nemkov, T.; Reisz, J.A.; Gehrke, S.; Hansen, K.C.; D’Alessandro, A. High-Throughput Metabolomics: Isocratic and Gradient Mass Spectrometry-Based Methods. Methods Mol. Biol. Clifton NJ 2019, 1978, 13-26.

46. Reisz, J.A.; Zheng, C.; D'Alessandro, A.; Nemkov, T. Untargeted and Semi-targeted Lipid Analysis of Biological Samples Using Mass Spectrometry-Based Metabolomics. Methods Mol. Biol. (Clifton NJ) 2019, 1978, 121-135.

47. Melamud, E.; Vastag, L.; Rabinowitz, J.D. Metabolomic Analysis and Visualization Engine for LC-MS Data. Anal. Chem. 2010, 82, 9818-9826. [CrossRef]

48. Reisz, J.A.; Chessler, K.M.; Dzieciatkowska, M.; D’Alessandro, A.; Hansen, K.C. Blood and Plasma Proteomics: Targeted Quantitation and Posttranslational Redox Modifications. Methods Mol. Biol. (Clifton NJ) 2017, 1619, $353-371$.

49. Chong, J.; Soufan, O.; Li, C.; Caraus, I.; Li, S.; Bourque, G.; Wishart, D.S.; Xia, J. MetaboAnalyst 4.0: Towards more transparent and integrative metabolomics analysis. Nucleic Acids Res. 2018, 46, W486-W494. [CrossRef]

50. Soukenik, M.; Diehl, A.; Leidert, M.; Sievert, V.; Büssow, K.; Leitner, D.; Labudde, D.; Ball, L.J.; Lechner, A.; Nägler, D.K.; et al. The SEP domain of p47 acts as a reversible competitive inhibitor of cathepsin L. FEBS Lett. 2004, 576, 358-362. [CrossRef]

51. Nemkov, T.; Hansen, K.C.; Dumont, L.J.; D’Alessandro, A. Metabolomics in transfusion medicine. Transfusion 2016, 56, 980-993. [CrossRef] [PubMed]

52. D'Alessandro, A.; Nemkov, T.; Yoshida, T.; Bordbar, A.; Palsson, B.O.; Hansen, K.C. Citrate metabolism in red blood cells stored in additive solution-3. Transfusion 2017, 57, 325-336. [CrossRef] [PubMed]

53. Whillier, S.; Raftos, J.E.; Sparrow, R.L.; Kuchel, P.W. The effects of long-term storage of human red blood cells on the glutathione synthesis rate and steady-state concentration. Transfusion 2011, 51, 1450-1459. [CrossRef] [PubMed]

54. Andrisse, S.; Koehler, R.M.; Chen, J.E.; Patel, G.D.; Vallurupalli, V.R.; Ratliff, B.A.; Warren, D.E.; Fisher, J.S. Role of GLUT1 in regulation of reactive oxygen species. Redox Biol. 2014, 2, 764-771. [CrossRef] [PubMed]

55. Zhang, Y.; Lee, J.-H.; Paull, T.T.; Gehrke, S.; D’Alessandro, A.; Dou, Q.; Gladyshev, V.N.; Schroeder, E.A.; Steyl, S.K.; Christian, B.E.; et al. Mitochondrial redox sensing by the kinase ATM maintains cellular antioxidant capacity. Sci. Signal. 2018, 11. [CrossRef]

56. Ullevig, S.L.; Kim, H.S.; Short, J.D.; Tavakoli, S.; Weintraub, S.T.; Downs, K.; Asmis, R. Protein S-Glutathionylation Mediates Macrophage Responses to Metabolic Cues from the Extracellular Environment. Antioxid. Redox Signal. 2016, 25, 836-851. [CrossRef] [PubMed]

57. Wither, M.; Dzieciatkowska, M.; Nemkov, T.; Strop, P.; D'Alessandro, A.; Hansen, K.C. Hemoglobin oxidation at functional amino acid residues during routine storage of red blood cells. Transfusion 2016, 56, 421-426. [CrossRef] 
58. Harper, V.M.; Oh, J.Y.; Stapley, R.; Marques, M.B.; Wilson, L.; Barnes, S.; Sun, C.-W.; Townes, T.; Patel, R.P. Peroxiredoxin-2 Recycling Is Inhibited During Erythrocyte Storage. Antioxid. Redox Signal. 2015, 22, $294-307$. [CrossRef]

59. Reisz, J.A.; Wither, M.J.; Dzieciatkowska, M.; Nemkov, T.; Issaian, A.; Yoshida, T.; Dunham, A.J.; Hill, R.C.; Hansen, K.C.; D'Alessandro, A. Oxidative modifications of glyceraldehyde 3-phosphate dehydrogenase regulate metabolic reprogramming of stored red blood cells. Blood 2016, 128, e32-e42. [CrossRef]

60. Aman, Y.; Qiu, Y.; Tao, J.; Fang, E.F. Therapeutic potential of boosting $\mathrm{NAD}^{+}$in aging and age-related diseases. Transl. Med. Aging 2018, 2, 30-37. [CrossRef]

61. Johnson, S.; Imai, S. NAD ${ }^{+}$biosynthesis, aging, and disease. F1000Research 2018, 7. [CrossRef] [PubMed]

62. Verdin, E. NAD ${ }^{+}$in aging, metabolism, and neurodegeneration. Science 2015, 350, 1208-1213. [CrossRef] [PubMed]

63. Yaku, K.; Okabe, K.; Nakagawa, T. NAD metabolism: Implications in aging and longevity. Ageing Res. Rev. 2018, 47, 1-17. [CrossRef] [PubMed]

64. Van der Goot, A.T.; Zhu, W.; Vázquez-Manrique, R.P.; Seinstra, R.I.; Dettmer, K.; Michels, H.; Farina, F.; Krijnen, J.; Melki, R.; Buijsman, R.C.; et al. Delaying aging and the aging-associated decline in protein homeostasis by inhibition of tryptophan degradation. Proc. Natl. Acad. Sci. USA 2012, 109, 14912-14917. [CrossRef] [PubMed]

65. Van der Goot, A.T.; Nollen, E.A.A. Tryptophan metabolism: Entering the field of aging and age-related pathologies. Trends Mol. Med. 2013, 19, 336-344. [CrossRef] [PubMed]

66. Grant, R.S.; Coggan, S.E.; Smythe, G.A. The Physiological Action of Picolinic Acid in the Human Brain. Int. J. Tryptophan Res. IJTR 2009, 2, 71-79. [CrossRef] [PubMed]

67. Kim, J.; Park, W. Indole: A signaling molecule or a mere metabolic byproduct that alters bacterial physiology at a high concentration? J. Microbiol. Seoul Korea 2015, 53, 421-428. [CrossRef] [PubMed]

68. Müller, H.E. Production and degradation of indole by gram-negative bacteria. Zentralbl. Bakteriol. Mikrobiol. Hyg. 1986, 261, 1-11. [CrossRef]

69. Dinarello, C.A. Interleukin 1 and interleukin 18 as mediators of inflammation and the aging process. Am. J. Clin. Nutr. 2006, 83, 447S-455S. [CrossRef]

70. Pietras, E.M. Inflammation: A key regulator of hematopoietic stem cell fate in health and disease. Blood 2017, 130, 1693-1698. [CrossRef]

71. Henry, C.J.; Nemkov, T.; Casás-Selves, M.; Bilousova, G.; Zaberezhnyy, V.; Higa, K.C.; Serkova, N.J.; Hansen, K.C.; D'Alessandro, A.; DeGregori, J.; et al. Folate dietary insufficiency and folic acid supplementation similarly impair metabolism and compromise hematopoiesis. Haematologica 2017, 102, 1985-1994. [CrossRef] [PubMed]

72. Chadefaux, B.; Rethoré, M.O.; Raoul, O.; Ceballos, I.; Poissonnier, M.; Gilgenkranz, S.; Allard, D. Cystathionine beta synthase: Gene dosage effect in trisomy 21. Biochem. Biophys. Res. Commun. 1985, 128, 40-44. [CrossRef]

73. McFadden, P.N.; Clarke, S. Methylation at D-aspartyl residues in erythrocytes: Possible step in the repair of aged membrane proteins. Proc. Natl. Acad. Sci. USA 1982, 79, 2460-2464. [CrossRef] [PubMed]

74. Lou, L.L.; Clarke, S. Enzymatic methylation of band 3 anion transporter in intact human erythrocytes. Biochemistry 1987, 26, 52-59. [CrossRef] [PubMed]

75. Janson, C.A.; Clarke, S. Identification of aspartic acid as a site of methylation in human erythrocyte membrane proteins. J. Biol. Chem. 1980, 255, 11640-11643. [PubMed]

76. Barber, J.R.; Clarke, S. Membrane protein carboxyl methylation increases with human erythrocyte age. Evidence for an increase in the number of methylatable sites. J. Biol. Chem. 1983, 258, 1189-1196. [PubMed]

77. D'Alessandro, A.; Nemkov, T.; Sun, K.; Liu, H.; Song, A.; Monte, A.A.; Subudhi, A.W.; Lovering, A.T.; Dvorkin, D.; Julian, C.G.; et al. AltitudeOmics: Red Blood Cell Metabolic Adaptation to High Altitude Hypoxia. J. Proteome Res. 2016, 15, 3883-3895. [CrossRef] [PubMed]

78. Reisz, J.A.; Slaughter, A.L.; Culp-Hill, R.; Moore, E.E.; Silliman, C.C.; Fragoso, M.; Peltz, E.D.; Hansen, K.C.; Banerjee, A.; D'Alessandro, A. Red blood cells in hemorrhagic shock: A critical role for glutaminolysis in fueling alanine transamination in rats. Blood Adv. 2017, 1, 1296-1305. [CrossRef] [PubMed]

79. Tretter, L.; Patocs, A.; Chinopoulos, C. Succinate, an intermediate in metabolism, signal transduction, ROS, hypoxia, and tumorigenesis. Biochim. Biophys. Acta 2016, 1857, 1086-1101. [CrossRef] 
80. Tannahill, G.M.; Curtis, A.M.; Adamik, J.; Palsson-McDermott, E.M.; McGettrick, A.F.; Goel, G.; Frezza, C.; Bernard, N.J.; Kelly, B.; Foley, N.H.; et al. Succinate is an inflammatory signal that induces IL-1 $\beta$ through HIF-1 $\alpha$. Nature 2013, 496, 238-242. [CrossRef]

81. Mills, E.; O’Neill, L.A.J. Succinate: A metabolic signal in inflammation. Trends Cell Biol. 2014, 24, $313-320$. [CrossRef]

82. D'Alessandro, A.; Moore, H.B.; Moore, E.E.; Reisz, J.A.; Wither, M.J.; Ghasasbyan, A.; Chandler, J.; Silliman, C.C.; Hansen, K.C.; Banerjee, A.; et al. Plasma succinate is a predictor of mortality in critically injured patients. J. Trauma Acute Care Surg. 2017, 83, 491-495. [CrossRef] [PubMed]

83. Nemkov, T.; Sun, K.; Reisz, J.A.; Yoshida, T.; Dunham, A.; Wen, E.Y.; Wen, A.Q.; Roach, R.C.; Hansen, K.C.; Xia, Y.; et al. Metabolism of Citrate and Other Carboxylic Acids in Erythrocytes As a Function of Oxygen Saturation and Refrigerated Storage. Front. Med. 2017, 4, 175. [CrossRef] [PubMed]

84. Antonelou, M.H.; Kriebardis, A.G.; Stamoulis, K.E.; Trougakos, I.P.; Papassideri, I.S. Apolipoprotein $\mathrm{J} /$ Clusterin is a novel structural component of human erythrocytes and a biomarker of cellular stress and senescence. PLoS ONE 2011, 6, e26032. [CrossRef] [PubMed]

85. Gonzalez-Armenta, J.L.; Mahapatra, G.; Allison Amick, K.; Li, N.; Lu, B.; Molina, A. HETEROCHRONIC PARABIOSIS: OLD BLOOD ATTENUATES MITOCHONDRIAL BIOENERGETICS OF YOUNG MICE. Innov. Aging 2018, 2, 558. [CrossRef]

86. Hofmann, B. Young Blood Rejuvenates Old Bodies: A Call for Reflection when Moving from Mice to Men. Transfus. Med. Hemother. 2018, 45, 67-71. [CrossRef] [PubMed]

87. Conese, M.; Carbone, A.; Beccia, E.; Angiolillo, A. The Fountain of Youth: A Tale of Parabiosis, Stem Cells, and Rejuvenation. Open Med. 2017, 12, 376-383. [CrossRef]

88. European Commission of the Press Announcements-Statement from FDA Commissioner Scott Gottlieb, M.D., and Director of FDA's Center for Biologics Evaluation and Research Peter Marks, M.D., Ph.D., Cautioning Consumers against Receiving Young Donor Plasma Infusions That are Promoted as Unproven Treatment for Varying Conditions. Available online: https://www.fda.gov/NewsEvents/Newsroom/ PressAnnouncements/ucm631568.htm (accessed on 8 April 2019).

(C) 2019 by the authors. Licensee MDPI, Basel, Switzerland. This article is an open access article distributed under the terms and conditions of the Creative Commons Attribution (CC BY) license (http://creativecommons.org/licenses/by/4.0/). 